\title{
Apoptosis control and proliferation marker in human normal and neoplastic adrenocortical tissues
}

\author{
GP Bernini*,', A Moretti', P Viacava², AG Bonadio², P lacconi ${ }^{3}$, P Miccoli ${ }^{3}$ and A Salvetti' \\ 'Department of Internal Medicine, University of Pisa, Via Roma 67, 56100 Pisa, Italy; ${ }^{2}$ Department of Oncology, University of Pisa, Via Roma 67, 56100 Pisa, \\ Italy; ${ }^{3}$ Department of Surgery, University of Pisa, Via Roma 67, 56100 Pisa, Italy
}

We evaluated by immunohistochemistry the expression of the $\mathrm{Bcl}-2$ and p53 proteins, as markers of apoptosis control, and of MIB-I, as a marker of cell proliferation, in a series of normal and neoplastic adrenocortical tissues. The specimens were 13 normal adrenals, 13 aldosterone-producing adenomas, 13 non-functioning adenomas and 16 carcinomas. Results were calculated as percentage of immunostained cells by using specific antibodies. No p53 protein was detected in any of the adrenocortical adenomas (functioning and non functioning) or normal adrenals, while p53 was overexpressed in 15 out of 16 carcinomas. In particular, 10 adrenal cancer specimens (62.5\%) showed strong staining in a high percentage (range 10-50\%) of the malignant cells. The percentage of $\mathrm{Bcl}-2$ positive cells was higher $(P<0.05$ or less) in non-functioning adenomas $(8.1 \pm 1.9 \%)$ and in carcinomas $(14.9 \pm 5.6 \%)$ than in normals $(2.9 \pm 0.9 \%)$ and aldosterone-producing adenomas $(5.3 \pm 1.3 \%)$ since four specimens of the non-functioning adenomas-group (30.7\%) and six of the carcinomas-group (37.5\%) showed over $10 \%$ positivity (cut-off for normal values, set at 90 th percentile of our controls). MIB-I positivity was $0.50 \pm 0.36 \%$ in normals, $0.54 \pm 0.08 \%$ in non-functioning adenomas and $0.54 \pm 0.08 \%$ in aldosterone-producing adenomas. MIB-I was expressed in all carcinomas with values $(13.7 \pm 3.1 \%)$ significantly $(P<0.0006)$ higher than in the other groups. In conclusion, the present data indicate that the apoptosis control and proliferation activity evaluated by the p53 and MIB-I proteins are impaired in adrenal carcinomas but preserved in adenomas, independently of their functional status. Therefore, these immunohistochemical markers, overexpressed in carcinomas only, may be useful in the diagnosis of malignancy in adrenocortical tumours. Whether $\mathrm{Bcl}-2$ positivity found in some carcinomas and non-functioning adenomas may constitute, in the latter, a negative prognostic marker is still unknown.

British Journal of Cancer (2002) 86, I56I- I565. DOl: 10.1038/sj/bjc/6600287 www.bjcancer.com

(c) 2002 Cancer Research UK

Keywords: P53; Bcl-2; Ki-67; adrenal cortex; adrenocortical tumours

The growth and diffusion of cancers, and consequently their aggressiveness, are dependent on a complicated balance between several mechanisms, such as neoangiogenesis, release of growth stimulating and inhibiting factors, apoptosis control and proliferation activity (Fox, 1997).

While malignant tumours of human adrenocortical glands are very rare (Wooten and King, 1993), benign adenomas, both nonfunctioning and functioning, are common in clinical practice. However, the apoptosis control and proliferation activity of neoplasms of the adrenal cortex have not been adequately investigated and results obtained to date are not univocal.

Mutations in the p53 tumour suppressor gene, which constitute the most common type of genetic alteration in several human cancers (Velculescu and El-Deiry, 1996), do not seem to be frequent in adrenocortical tumours (Ohgaki et al, 1993; Reincke et al, 1994; Reincke et al, 1996). Different results were found in studies on pathological adrenal cortex (Lin et al, 1994; Reincke et al, 1994, 1996; Barzon et al, 2001) for what concerns p53 overexpression, a well-established immunohistochemical marker of p53 mutations (Davidoff et al, 1991),

$\mathrm{Bcl}-2$, a cellular oncogene which encodes for proteins that inhibit apoptosis, thereby determining resistance to programmed cell

*Correspondence: GP Bernini; E-mail: g.bernini@med.unipi.it

Revised I I February 2002; accepted 27 February 2002 death (Hockenbery et al, 1990, 1993), is overexpressed in different types of solid tumours (Pilotti et al, 1994; Vargas et al, 1997). However, Bcl-2 immunoreactivity has been demonstrated not only in adrenal cortical lesions (cortical hyperplasia, adenomas and carcinomas) but also in normal cortical tissue (Fogt et al, 1998).

MIB-1, which recognises a nuclear antigen (Ki-67) associated with all phases of the cell cycle except in resting cells (Gerdes et $a l, 1984)$, is overexpressed in several human tumours and is commonly considered very useful in the evaluation of tumour cell growth (Hall and Woods, 1990). Recently it has also been reported that MIB-1 expression differentiates benign from malignant adrenocortical tumours but not adenomas from normal cortex (Iino et al, 1997; Nakazumi et al, 1998).

The aim of our study was to evaluate, by immunohistochemistry, expression of the $\mathrm{Bcl}-2$ and $\mathrm{p} 53$ proteins as markers of apoptosis control and of MIB-1 protein as a marker of cell proliferation, in a series of human normal and neoplastic (adenomas and carcinomas) adrenocortical tissues.

\section{MATERIALS AND METHODS}

\section{Patients and pathology}

The study, approved by the local Ethical Committee, involved 55 patients with aldosterone-producing adenomas $(n=13$, APA), nonfunctioning cortical adenomas $(n=13, \mathrm{NFA})$ and adrenocortical 
carcinomas $(n=16, C A)$. As controls, 13 normal adrenal glands $(\mathrm{N})$ were studied after removal from patients with renal carcinomas. Clinical and pathological details of our population are shown in Table 1.

Patients with APA showed the typical pattern of the disease with hypertension (systolic blood pressure $174 \pm 7.0 \mathrm{mmHg}$, mean \pm s.e., diastolic blood pressure $107 \pm 3.5 \mathrm{mmHg}$ ) hypokaliemia $\left(2.9 \pm 0.2 \mathrm{mmol} \mathrm{l}^{-1}\right)$, low PRA levels $\left(0.18 \pm 0.06 \mathrm{ng} \mathrm{ml} \mathrm{h}^{-1}\right)$ and high plasma aldosterone $\left(1298 \pm 172 \mathrm{pmol}^{-1}\right)$. In patients with NFA adrenal masses had been incidentally discovered and endocrinological investigation had revealed normal catecholamines, glucocorticoids, androgens and mineralcorticoids in all cases. Patients with CA had been investigated for abdominal pain in 11 cases and for hyperandrogenism in five cases. Pathological diagnosis of our tumours was based on accepted criteria including tumour mass, presence of metastasis or recurrence, mitotic ratio, nuclear grade, necrosis and capsula and/or vascular invasion (Lack, 1997). In particular, tumour necrosis was absent in two, low in two, moderate in four and wide in eight cases. Staging of CA, according to the Mac-Farlane criteria (Mac-Farlane, 1958), indicated stage II in six cases, stage III in eight cases and stage IV in two patients.

After surgery, all NFA and APA were cured while 13 CA died of local and/or diffuse metastases with a mean( \pm s.d.) survival of $27.2 \pm 31.0$ months (range 3-100 months). Three patients were alive at time of writing of the manuscript (follow-up performed 10 months after surgery).

\section{Specimens}

A total of 55 formalin-fixed, paraffin-embedded blocks of adrenal tissues were studied. Five $\mu \mathrm{m}$ sections were stained with haematoxilin-eosin for histological evaluation. Five additional $\mu \mathrm{m}$ sections were used for immunohistochemistry.

\section{Immunohistochemistry}

Antibodies The sections were incubated with the following primary monoclonal antibodies: MAb 124 (DBA, dilution $1: 100$ ) for Bcl-2, MAb DO7 (Novocastra Laboratories, dilution 1:100) for p53, and MIB-1 (DBA, dilution 1:200) for Ki-67. Incubation time was $12-24 \mathrm{~h}$ at $4^{\circ} \mathrm{C}$.

\section{Method}

Tissue sections stained for MIB-1 were pretreated using 0.1 trypsin with 0.1 calcium chloride buffered to $\mathrm{pH}$ 7.6. In order to unmask the antigens, the slides were microwave treated in $10 \mathrm{~mm}$ citrate buffer, pH6, for a total of $10 \mathrm{~min}$. MIB-1 and p53 sections were incubated with biotin-labelled secondary antibody (dilution 1:500) and avidin-biotin complex (Vector Burlingame, CA, USA) for $30 \mathrm{~min}$ respectively. 3-3' diaminoben-

Table I Clinical and pathological details of normal subjects $(N)$ and of patients with aldosterone-producing adenoma (APA), non-functioning adrenocortical adenoma (NFA) and adrenocortical carcinoma (CA). Mean \pm s.e.m. and range (in parentheses) are shown

\begin{tabular}{lcccc}
\hline & N & APA & NFA & CA \\
\hline Age (years) & $59.8 \pm 3.0$ & $47.4 \pm 2.6^{*} *$ & $49.9 \pm 2.9^{*}$ & $53.4 \pm 4.4$ \\
& $(38-70)$ & $(27-59)$ & $(30-72)$ & $(19-77)$ \\
male/female & $9 / 4$ & $8 / 5$ & $6 / 7$ & $9 / 7$ \\
side (R/L) & - & $4 / 9$ & $6 / 7$ & $8 / 8$ \\
tumour size (mm) & - & $20.0 \pm 2.2$ & $41.1 \pm 3.2^{\circ}$ & $120.8 \pm 13.3^{\circ} \dagger$ \\
& & $(5-30)$ & $(25-60)$ & $(60-250)$ \\
\hline
\end{tabular}

*P $<0.02 ; * * P<0.004$ vs $N .{ }^{\circ} P<0.0001$ vs APA. $\dagger P<0.000$ I vs NFA. zidine tetrahydrochloride with 0.01 hydrogen peroxide was used as chromogen. The alkaline phosphatase-anti-alkaline phosphatase (APAAP) method was used to amplify the Bcl-2 signal. The reaction was developed with alkaline phosphatase containing naphthol, AS-MX, fast red, and levamisol (APAAP kits DAKO, Milan, Italy).

\section{Controls}

Positive controls consisted of invasive breast carcinoma known to express MIB-1 and p53 antigens. Positive control for Bcl-2 was follicular non-Hodgkin lymphoma. Negative controls were obtained by omitting primary antibodies.

\section{Evaluation of parameters}

The positivity index was obtained by counting almost 500 cells of lesions of normal tissue on three $\times 250$ fields and calculating the percentage of cells with nuclear (p53 and MIB-1) and cytoplasmatic (Bcl-2) immunoreactivity. Since in our normal tissues no immunoreactivity was found for p53 and MIB-1, the specimens were considered positive when at least $1 \%$ of cells showed distinct nuclear staining. However, in order to reduce possible false positive results, we also analysed our data by moving the cut-off of normality to $5 \%$. In contrast, for $\mathrm{Bcl}-2$ the specimens were considered positive when at least $11 \%$ of cells showed intense cytoplasmatic immunoreactivity, as the cut-off of normal values, calculated as 90th percentile of our controls, proved to be $10 \%$. All parameters were determined independently by two pathologists (VP and BA) and discordant cases were solved by simultaneous review of the specimens. Cases with interobserver differences greater than $5 \%$ were re-evaluated.

\section{Statistics}

All data are expressed as mean \pm s.e.m. Values obtained for each variable to compare groups were analysed by using the unpaired $t$-test and Wilcoxon's test. Spearman correlation coefficients $(r)$ were used as parameters of association. Statistical difference was accepted at $P<0.05$.

\section{RESULTS}

Age in the APA and NFA-groups was significantly lower than in N and, among adrenal lesions, tumour size in CA was highest while that in APA proved to be the lowest (Table 1).

No p53 protein was detected in any sample of N, APA and NFA. In contrast, p53 was expressed in 15 out of 16 (94\%) CA and in 10 specimens the staining involved between $10-50 \%$ of the malignant cells (Figures 1 and 2). Even considering our cut-off of positivity $\geqslant 5 \%$, p53 expression was still elevated, corresponding to 11 out of 16 cases $(68.7 \%)$

APA $(5.3 \pm 1.3 \%)$ and $N(2.9 \pm 0.9 \%)$-groups showed an average percentage of $\mathrm{Bcl}-2$ positive cells lower than NFA $(8.1 \pm 1.9 \%)$ and CA $(14.9 \pm 5.6 \%)$-groups. No difference was found between NFA and CA (Figure 3). Analytical data showed that four specimens of the NFA-group $(30.7 \%)$ and six of the CA-group (37.5\%) had positivity over $10 \%$ (our cut-off of normal values) (Figure 3 below)

MIB-1 expression was very low $(\leqslant 1 \%)$ in cortical adenomas (APA and NFA) and in normal specimens, while strong immunoreactivity $(3-40 \%)$ was detected in all CA with mean values $(13.7 \pm 3.0 \%)$ significantly $(P<0.0001)$ higher than in normal adrenals $(0.5 \%)$, APA $(0.53 \pm 0.08 \%)$ and NFA $(0.53 \pm 0.08 \%)$ (Figures 4 and 5$)$.

No correlation was found between p53, MIB-1 and Bcl-2 or between these immunohistochemical markers and clinical or pathological variables in the APA and NFA-groups. Positive asso- 


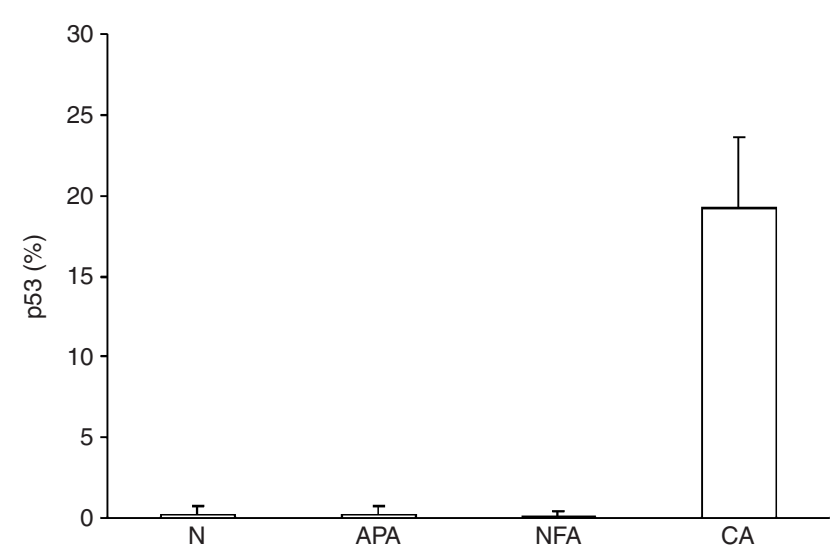

Figure I Mean percentage ( \pm s.e.m.) of $\mathrm{p} 53$ positive cells in normal cortex $(\mathrm{N})$, Aldosterone-producing adenomas (APA), non-functioning adenomas (NFA) and carcinomas (CA).

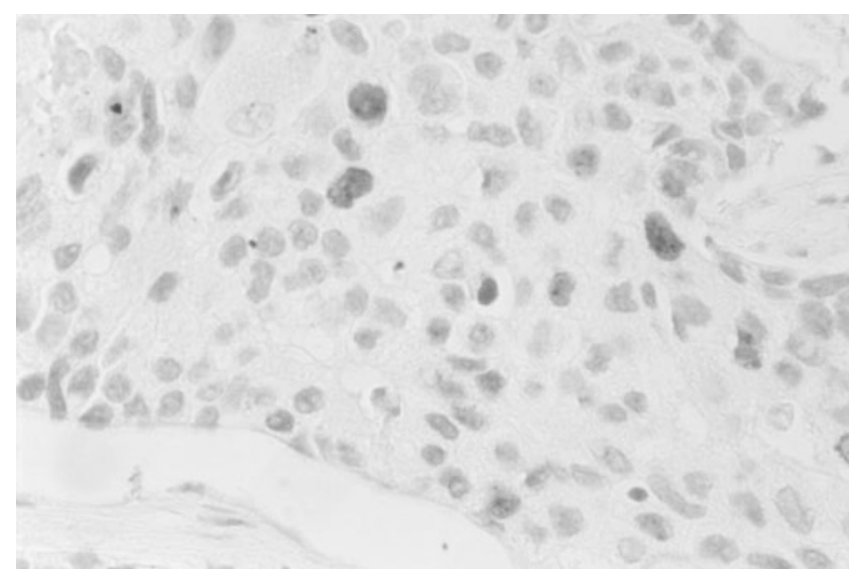

Figure 2 Adrenocortical carcinoma with several p53 immunoreactive cells.

ciations between $\mathrm{p} 53$ and MIB-1 $(r=0.560, P<0.02)$ and between p53 and tumour necrosis $(r=0.530, P<0.03)$ were detected in CA.

\section{DISCUSSION}

The aim of our study was to investigate apoptosis control and proliferation activity in a group of human adrenal neoplasms, using an immunohistochemical approach. This method presents some intrinsic limits, both because it does not always reflect a corresponding genetic alteration and because it does not permit exact quantification of the proteins in the tissues. However, immunohistochemistry sometimes appears to be the only procedure able to detect specific proteins involved in tumorogenesis and offers the advantage of detecting the exact intratissutal localisation and the intracellular distribution of several markers.

It is well-known that the human tumour suppressor p53 is deemed critical for maintaining genomic stability and homeostasis (Agarwal et al, 1998). Accordingly, mutations in the p53 gene constitute the most common type of genetic alteration in human cancers (Hollstein et al, 1991; Velculescu and El-Deiry, 1996). However, few data refer to adrenocortical CA and those reported indicate that p53 mutations are uncommon in these tumours (Ohgaki et al, 1993; Reincke et al, 1994). Different findings were observed by immunohistochemistry. Our study shows frequent
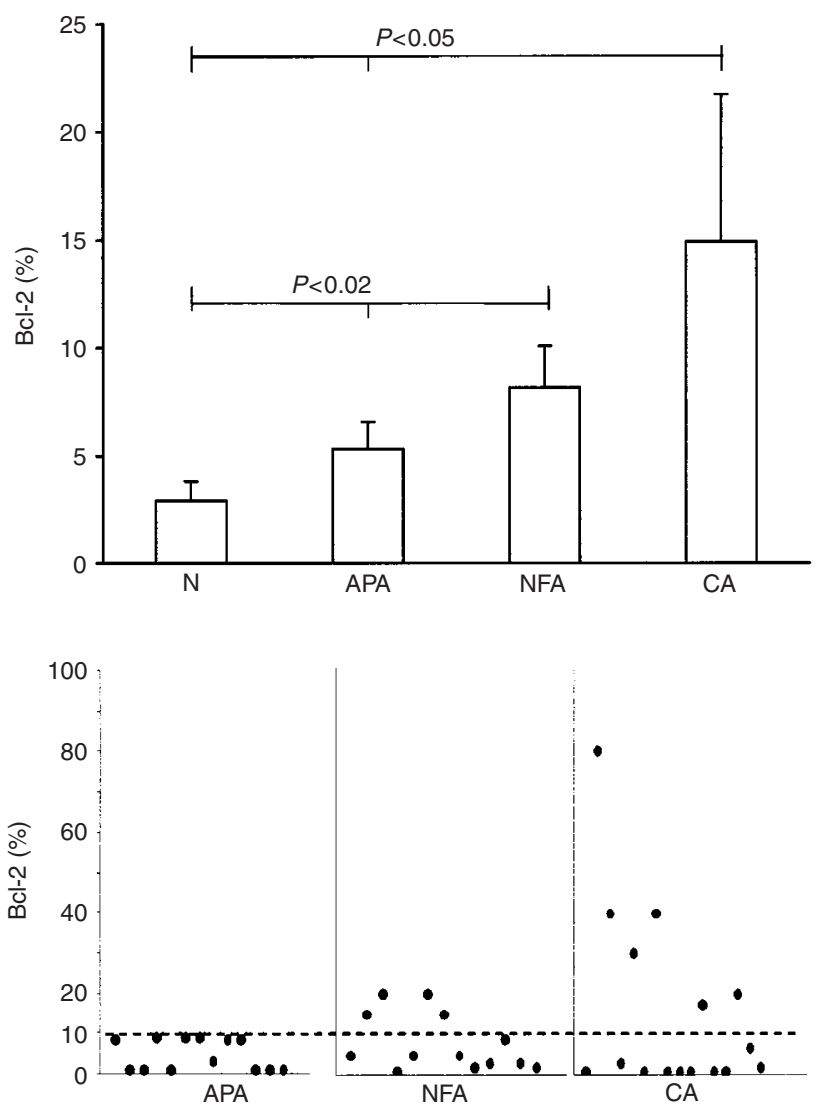

Figure 3 Mean percentage ( \pm s.e.m.) of $\mathrm{Bcl}-2$ positive cells in normal cortex (N), Aldosterone-producing adenomas (APA), non-functioning adenomas (NFA) and carcinomas (CA). The statistical difference is shown (above). Bcl-2 individual data in APA, NFA and CA: the dotted line represents the upper limit of normal calculated as 90th percentile of our controls (below).

p53 immunoreactivity in CA and other authors (Reincke et al, 1994) reported p53 positivity in about half of their cases. The definition of positive immunohistochemical staining in this study was $\geqslant 1 \%$ because no immunostaining was detected in the specimens of our controls. However, even when the cut-off of p53 positivity was moved to $5 \%$ in order to reduce possible false positive results, we obtained similar results with high frequency of immunoreactivity in CA $(68.7 \%)$. Since genetic analysis of the specimens could not be performed, we cannot establish whether the p53 overexpression we found represents underlying gene mutations or results from abnormal stabilisation of the wild-type protein leading to an increase in its half-life. In any case, our finding indicates that p53 immunoreactivity is a feature of CA. Different results have been reported in APA where no or poor p53 immunoreactivity was found not only in adenomas without p53 mutations (Reincke et al, 1996) but also in those with ascertained genetic alterations (Lin et al, 1994; Adleff et al, 1998). The present data confirm these observations since immunohistochemistry failed to show p53 positive cells in all 13 APA. All these findings imply that in APA p53 mutations are likewise uncommon but do not exclude the possibility that in these adenomas the immunohistochemical method may have low sensitivity. Indeed a mutant p53 protein may be not recognisable by the antibody, deletion mutations do not necessarily induce abnormal p53 protein and in the case of missense mutations several events may be required for p53 overexpression (Casey et al, 1996). More homogeneous data on the p53 protein have been observed in NFA. No genetic p53 mutation and no p53 immunoreactivity was detected in isolated cases (Reincke et 


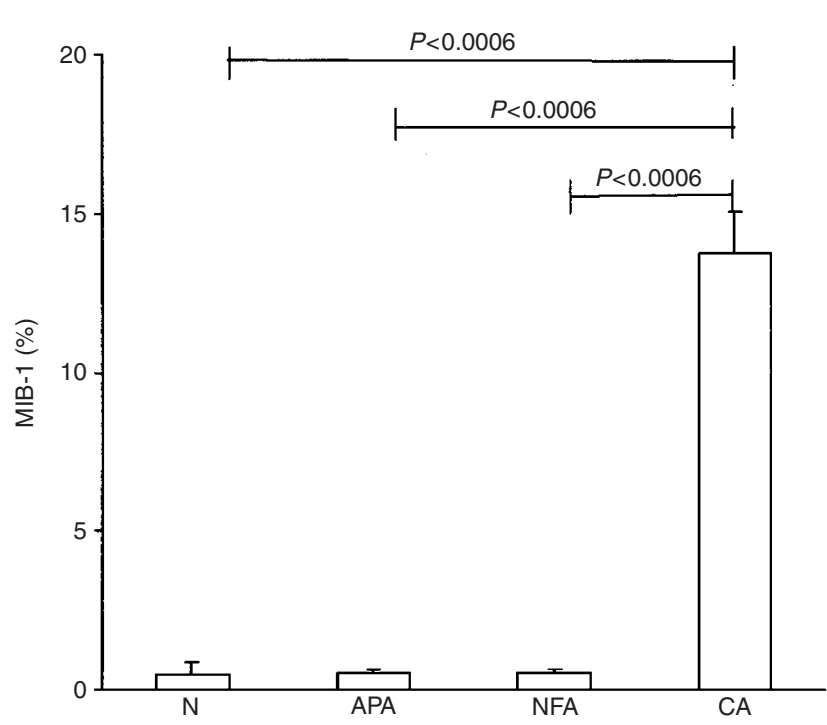

Figure 4 Mean percentage ( \pm s.e.m.) of MIB-I positive cells in normal cortex $(\mathrm{N})$, Aldosterone-producing adenomas (APA), non-functioning adenomas (NFA) and carcinomas (CA). The statistical difference is shown.

$a l, 1994)$ and in a group of NFA (Adleff et al, 1998). Our results fit with these data since none of the NFA patients studied was positive for p53 immunoreactivity.

Taken together, the present results indicate that p53 is a useful immunohistochemical marker to distinguish benign from malignant adrenal tumours since it proved to be overexpressed in several carcinomas and never expressed in functioning and nonfunctioning adenomas.

$\mathrm{Bcl}-2$ is a cellular oncogene which encodes for proteins that inhibit apoptosis, thus determining resistance to programmed cell death (Hockenbery et al, 1990, 1993). Bcl-2 expression has been reported in normal tissues but also in different types of solid tumours (Pilotti et al, 1994; Vargas et al, 1997). However few studies have investigated this protein in adrenal glands. The most extensive study (Fogt et al, 1998) indicated that Bcl-2 is overexpressed in normal adrenal cortex, without distinct staining difference between normal and pathological tissue (hyperplasia, adenomas and carcinomas). Our results confirm that Bcl-2 positivity is detectable in normal adrenals. In contrast, cortical adenomas and carcinomas showed heterogeneous Bcl-2 expression. Some CA $(37.5 \%)$ and NFA $(30.7 \%)$ had strong positivity, while in the remaining and in all APA the number of $\mathrm{Bcl}-2$ positive cells was similar to normal tissue. The prognostic significance of this particular immunohistochemical pattern observed in some NFA is unknown.

Evaluating our data, we observed a strong discrepancy in the expression rate of $\mathrm{Bcl}-2$ and $\mathrm{p} 53$ in CA. We have no clear explana-

\section{REFERENCES}

Adleff V, Racz K, Szende B, Toth M, Moldvay J, Varga I, Bezzegh A, Szegedi Z, Glaz E (1998) Coexpression of p53 and tissue transglutaminase genes in human normal and pathologic adrenal tissues. J Steroid Biochem Molec Biol 66: $27-33$

Agarwal ML, Taylor WR, Chernow MV, Chernova OB, Stark GR (1998) The p53 network. J Biol Chem 273: $1-4$

Barzon L, Chilosi M, Fallo F, Martignoni G, Montagna L, Palu' G, Boscaro M (2001) Molecular analysis of CDKN1C and TP53 in sporadic adrenal tumors. Eur J Endocrinol 145: 201-212

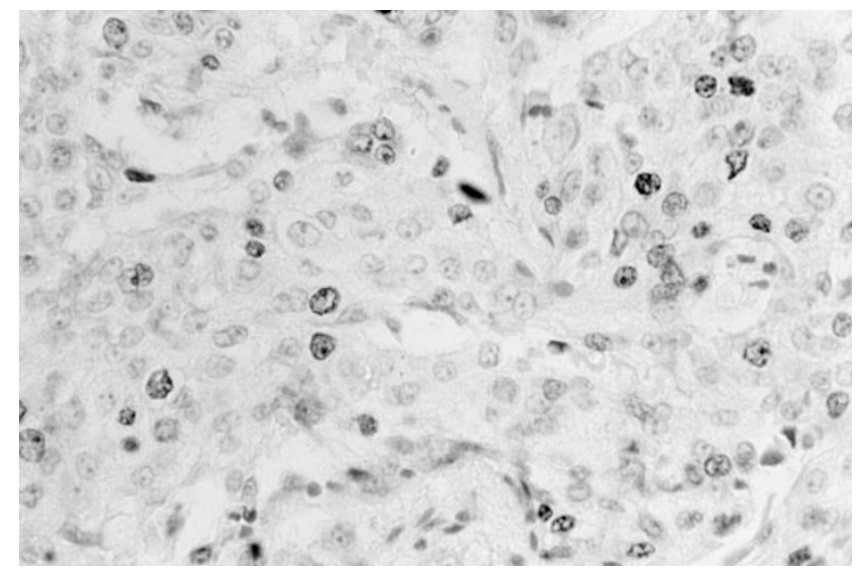

Figure 5 Adrenocortical carcinoma with immunoreactive MIB-I cells.

tion for this finding, although it may depend on the fact that the two markers involve different and independent mechanisms of apoptosis control. Thus, in human tumours the expression of Bcl-2 and mutant p53 does not always coexist, even if both markers block programmed cell death. Accordingly, a lack of relation and even an inverse association between Bcl-2 and p53 were found in breast carcinomas (Leek et al, 1994; Siziopiku et al, 1996; Viacava et al, 1999) and in parathyroid adenomas (Naccarato et al, 1998).

A useful tool to examine cell proliferation activity consists in immunohistochemical analysis by MIB-1, an antibody that recognises Ki-67, a cell cycle-related nuclear antigen (Gerdes et al, 1984; Hall and Woods, 1990). A recent study reported no difference in MIB-1 expression between normal cortex and functioning (Iino et al, 1997; Nakazumi et al, 1998) and non-functioning cortical adenomas (Gerdes et al, 1984). In contrast, MIB-1 may differentiate adenomas from carcinomas of the adrenal cortex and may predict the biological behaviour of adrenocortical CA (Suzuki et al, 1992; Goldblum et al, 1993; Sasano et al, 1995; Iino et al, 1997; Nakazumi et al, 1998). Our results confirm these data, showing that in cortical adenomas, independently of their function, MIB-1 expression is similar to that in normal cortex, while in malignant tumours MIB-1 positivity appears to be strongly and constantly present.

In conclusion, the present data indicate that the apoptosis control and proliferation activity evaluated by the p53 and MIB1 proteins are impaired in CA but preserved in adenomas, independently of their functional status. Therefore, these immunohistochemical markers, overexpressed in CA only, may be useful in the diagnosis of malignancy in adrenocortical tumours. Finally, our results show that Bcl-2 overexpression may occur in CA but also in some NFA. Whether Bcl-2 positivity constitutes a negative prognostic marker in NFA is, at present, unknown.
Casey G, Lopez ME, Ramos JC, Plummer SJ, Arboleda MJ, Shaughnessy M, Karlan B, Slamon DJ (1996) DNA sequence analysis of exons 2 through 11 and immunohistochemical staining are required to detect all known p53 alterations in human malignancies. Oncogene 13: 1971-1981

Davidoff AM, Humphrey PA, Iglehart JD, Marks JR (1991) Genetic basis for p53 overexpression in human breast cancer. Proc Natl Acad Sci USA 88: $5006-5010$ 
Fogt F, Vortmeyer AO, Poremba C, Minda M, Harris CA, Tomaszewski JE (1998) Bcl-2 expression in normal adrenal glands and in adrenal neoplasms. Mod Pathol 11: 716-720

Fox SB (1997) Tumour angiogenesis and prognosis. Histopathology 30: $294-$ 301

Gerdes J, Lemke H, Baisch H, Wacker HH, Schwab V, Stein H (1984) Cell cycle analysis of a cell proliferation-associated human nuclear antigen defined by the monoclonal antibody Ki-67. J Immunol 133: 1710-1715

Goldblum JR, Shannon R, Kaldjian EP, Thiny M, Davenport R, Thompson N, Lloyd RV (1993) Immunohistochemical assessment of proliferative activity in adrenocortical neoplasms. Mod Pathol 6: 663-668

Hall PA, Woods AL (1990) Immunohistochemical markers of cellular proliferation: achievements, problems and prospects. Cell Tissue Kinet 23: 505509

Hockenbery DM, Nunez G, Milliman C, Schreiber RD, Korsmeyer SJ (1990) $\mathrm{Bcl}-2$ is an inner mitochondrial membrane protein that blocks programmed cell death. Nature 348: 334-337

Hockenbery D, Oltvai Z, Yin XM, Milliman L, Korsmeyer SJ (1993) Bcl-2 functions in an antioxidant pathway of apoptosis. Cell 75: 241-251

Hollstein M, Sidransky D, Vogelstein B, Harris CC (1991) P53 mutations in human cancers. Science 253: 49-53

Iino K, Sasano H, Yabuki N, Oki Y, Kikuchi A, Yoshimi T, Nagura H (1997) DNA topoisomerase II $\beta$ and Ki-67 in human adrenocortical neoplasms: a possible marker of differentiation between adenomas and carcinomas. Mod Pathol 10: $901-907$

Lack EE (1997) Tumors of the adrenal gland and extra-adrenal paraganglia. In Atlas of tumor Pathology, AFIP fascicle 19, 3rd series. Washington, DC: Armed Forces Institutes of Pathology

Leek DR, Kaklamanis L, Pezzella F, Gatter KC, Harris AL (1994) Bcl-2 in normal breast and carcinoma, association with estrogen receptor-positive, epidermal growth factor receptor-negative tumours and in situ cancer. $\mathrm{Br} J$ Cancer 69: $135-139$

Lin S-R, Lee Y-J, Tsai J-H (1994) Mutations of the p53 gene in human functional adrenal neoplasms. J Clin Endocrinol Metab 78: 483-491

Mac-Farlane DA (1958) Cancer of the adrenal cortex: the natural history, prognosis and treatment in a study of fifty-five cases. Ann R Coll Surg Engl 23: $155-186$
Naccarato AG, Marcocci C, Miccoli P, Bonadio AG, Cianferotti L, Vignali E, Cipollini G, Viacava P (1998) Bcl-2, p53 and MIB-1 expression in normal and neoplastic parathyroid tissues. J Endocrinol Invest 21: 136-141

Nakazumi H, Sasano H, Iino K, Oshashi Y, Orikasa S (1998) Expression of cell cycle inhibitor p27 and Ki-67 in human adrenocortical neoplasm. Mod Pathol 11: $1165-1170$

Ohgaki H, Kleihues P, Heitz PU (1993) P53 mutations in sporadic adrenocortical tumors. Int J Cancer 54: $408-410$

Pilotti S, Collini P, Rilke F, Cattoretti G, Del Bo R, Pierotti MA (1994) Bcl-2 protein expression in carcinomas originating from the follicular epithelium of the thyroid gland. J Pathol 172: 337-342

Reincke M, Karl M, Travis WH, Mastorakos G, Allolio B, Linehan HM, Chrousos GP (1994) P53 mutations in human adrenocortical neoplasms: immunohistochemical and molecular studies. J Clin Endocrinol Metab 78: $790-794$

Reincke M, Wachenfeld C, Mora P, Thumser A, Jaursch-Hancke C, Abdelhamid S, Chrousos GP, Allolio B (1996) P53 mutations in adrenal tumors: caucasian patients do not show the exon 4 'Hot Spot' found in Taiwan. J Clin Endocrinol Metab 81: 3636-3638

Sasano H, Imatani A, Shizawa S, Suzuki T, Nagura H (1995) Cell proliferation and apoptosis in normal and pathologic human adrenal. Mod Pathol 8: 11-17

Siziopiku KP, Prioleau JE, Harris JR, Schnitt SJ (1996) Bcl-2 expression in the spectrum of preinvasive breast lesions. Cancer 77: 499-506

Suzuki T, Sasano H, Nisikawa T, Rhame J, Wilkinson DS, Nagura H (1992) Discerning malignancy in human adrenocortical neoplasms: utility of DNA flow cytometry and immunohistochemistry. Mod Pathol 5: 224-230

Vargas MP, Vargas HI, Kleiner DE, Merino MJ (1997) The role of prognostic markers (MIB-1, RB, and bcl-2) in the diagnosis of parathyroid tumors. Mod Pathol 10: $12-17$

Velculescu VE, El-Deiry WS (1996) Biological and clinical importance of the p53 tumor suppressor gene. Clin Chem 42: 858-868

Viacava P, Naccarato AG, Bevilacqua G (1999) Different proliferative patterns characterize different preinvasive breast lesions. J Pathol 188: 245-251

Wooten MD, King DK (1993) Adrenal cortical carcinoma. Cancer 72: 3145 3155 